\title{
MENINGKATKAN SERVICE QUALITY MANAGEMENT USAHA LAUNDRY DENGAN SISTEM APLIKASI ONLINE
}

\author{
Padli ${ }^{1}$,Said Muhammad ${ }^{2}$ Novi Shintia ${ }^{3}$,Sari Hepy Maharani ${ }^{4}$ \\ Jurusan Administrasi Bisnis Politeknik Negeri Banjarmasin 1,2,3,4 \\ padlipoliban@gmail.com ${ }^{1}$ \\ saidmuhammad@gmail.com ${ }^{2}$ \\ novishintia@yahoo.co.id ${ }^{3}$ \\ smaharani.83@gmail.com $^{4}$
}

\begin{abstract}
Market needs for laundry services, especially in big cities, will always exist. Laundry business is a promising business, but unfortunately management in this business is still not optimal because it is managed by individuals manually. Constraints that are often faced in this business are financial reports, operational management and customer service management. This community service is carried out with the aim to develop a web-based laundry and sms gateway application system that allows owners to manage laundry from anywhere and interact with their customers. Training on the use of this application is also given to laundry employees to help them use laundry applications as tools in their daily work. The results of this community service are proven that laundry applications can help improve overall laundry business management and improve the competitiveness of the business because of the increasingly varied and unique touch of technology that makes the laundry business competition more innovative.
\end{abstract}

Keywords: information system, web, sms gateway, laundry management

\begin{abstract}
ABSTRAK
Kebutuhan pasar akan jasa cuci baju terutama di kota-kota besar akan selalu ada. Bisnis laundry adalah bisnis yang menjanjikan, namun sayangnya manajemen dalam bisnis ini banyak yang masih belum maksimal karena dikelola oleh individu secara manual. Kendala yang seringkali dihadapi dalam bisnis ini adalah laporan keuangan, manajemen operasional serta manajemen layanan pelanggan. Pengabdian masyarakat ini dilakukan dengan tujuan untuk membangan sistem aplikasi laundry berbasis web dan sms gateway yang memungkinkan pemilik mengelola laundry darimana saja serta berinteraksi dengan pelanggan. Pelatihan tentang penggunaan aplikasi ini juga diberikan kepada para karyawan laundry untuk membantu mereka dalam menggunakan aplikasi laundry sebagai tools dalam pekerjaan mereka sehari-hari. Hasil pengabdian masyarakat ini adalah terbukti bahwa aplikasi laundry dapat membantu meningkatkan manajemen usaha laundry secara keseluruhan serta meningkatkan daya saing bisnis tersebut karena adanya sentuhan teknologi yang semakin bervariasi dan unik membuat persaingan bisnis laundry makin inovatif.
\end{abstract}

Kata Kunci: sistem informasi, web, sms gateway, manajemen laundry 


\section{PENDAHULUAN}

\section{Analisis Situasi}

\section{Analisis Situasi Mitra 1}

Mitra 1 dimiliki oleh seorang sarjana yang tertarik untuk berwiraswasta. Usaha mikro yang beliau dirikan masih baru berusia 6 bulan. Dikarenakan masih baru, maka karyawan juga masih sedikit. Karyawan berjumlah 3 orang perempuan yang merangkap posisi sebagai kasir, operator mesin, dan karyawan setrika. Dikarenakan masih baru dan masih terus berkembang, omset usaha mikro Mitra 1 berkisar antara $4-6$ juta rupiah per bulan. Sebuah nilai yang tidak sedikit untuk usaha yang masih terbilang baru dibuka.

Lokasi mitra 1 berada sedikit di pinggir kota Banjarmasin dengan segmen pelanggan rumah tangga biasa dan karyawan/pegawai. Bagi mereka, lebih murah dan praktis mencucikan baju di laundry daripada harus membeli mesin cuci/ memperkerjakan seorang pembantu rumah tangga.

\section{Analisis Situasi Mitra 2}

Mitra 2 dimiliki oleh seorang dengan latar sarjana sosial. Usaha mikro yang beliau dirikan sudah berusia 4 tahun sehingga kondisinya sudah relatif stabil dibanding Mitra 1. Mitra 2 memiliki karyawan 4 orang yang terdiri dari 2 karyawan perempuan dan 2 karyawan laki-laki. Karyawan laki-laki bertindak sebagai kasir dan operator mesin cuci, sedangkan karyawan perempuan bertindak sebagai operator mesin cuci dan karyawan setrika. Dikarenakan sudah berusia 4 tahun, omset Mitra II sudah bisa mencapai 10 juta rupiah per bulan.

Mitra II adalah laundry kiloan yang berada di tengah kota Banjarmasin dengan segmen umumnya adalah pelanggan mahasiswa. Mahasiswa adalah segmen yang potensial untuk usaha mikro laundry kiloan karena dekat dengan kampus ULM, aktivitas mereka yang padat sehingga tidak memiliki waktu untuk mencuci/ menyetrika baju mereka sendiri.

\section{Permasalahan mitra}

a. Kesulitan pembuatan laporan keuangan

- Pembuatan nota dan laporan keuangan masih manual sehingga rentan terhadap kesalahan atau kecurangan dari karyawan

b. Manajemen Operasional belum maksimal

- Manajemen antrian laundry tidak terkontrol sehingga kadang pakaian yang baru datang dikerjakan terlebih dahulu dan yang sudah antri lebih lama tidak dikerjakan belakangan. Efeknya, ketika pelanggan mengambil pakaian ternyata pakaian tersebut belum jadi/belum dikerjakan

- Ketika pakaian diambil pelanggan, karyawan membutuhkan waktu yang lama untuk mencarinya. Hal ini dikarenakan tidak ada pencatatan yang bagus mengenai lokasi rak dari pakaian yang sudah selesai dikerjakan.

c. Perlunya peningkatan teknologi

- Bagi perusahaan yang sudah memiliki aplikasi, aplikasi yang ada masih terlalu general dan masih memiliki banyak kekurangan fitur 
- Beberapa pelanggan kecewa ketika datang ternyata pakaian belum jadi. Sehingga, sudah menjadi kebiasaan pelanggan telepon/sms terlebih dahulu untuk menanyakan status dari pakaiannya sebelum mengambil ke laundry

- Kontrol aktivitas laundry kurang ketika pemilik tidak berada di lokasi usaha

\section{SOLUSI MASALAH}

Berdasarkan uraian masalah diatas maka untuk mengatasinya adalah dengan menggunakan metode difusi IPTEK yaitu dengan membuat produk Aplikasi Manajemen Laundry berbasis Web dan Aplikasi Layanan SMS Pelanggan berbasis SMS Gateway yang memiliki fitur sebagai berikut :

1. Manajemen Pelanggan, adalah menu untuk pengelolaan data pelanggan dengan sub menu:

a. Registrasi Pelanggan, untuk memasukkan data pelanggan baru

b. Edit Data Pelanggan, untuk melakukan pengubahan data pelanggan

2. Transaksi Laundry, adalah menu untuk pengelolaan pakaian yang dilaundry dengan sub menu:

a. Pembuatan Nota, untuk membuat nota ketika ada laundry pakaian masuk

b. Data Nota Harian, untuk melihat data laundry yang masuk per hari

c. Pengubahan Nota, untuk mengubah nota bila ada perubahan/kesalahan

d. Pembatalan Nota, untuk membatalkan nota apabilaada kesalahan/pelanggan membatalkan laundry

e. Pencarian Nota, untuk mencari data nota yang pernah dibuat

f. Antrian Laundry, untuk melihat antrian pakaian yang akan dilaundry

g. Pengambilan Laundry, untuk melihat data laundry yang sudah jadi dan siap diambil pelanggan

3. Keuangan, adalah menu untuk mengelola keuangan kasir dengan sub menu:

a. Keuangan Kasir, untuk mengetahui keuangan kasir saat itu.

b. Entri Pengeluaran, untuk mengentrikan pengeluaran yang dilakukan kasir

4. Laporan, adalah menu untuk mengetahui lapoaran harian laundry dengan sub menu:

a. Lap. Keuangan Harian, untuk mengetahui laporan keuangan laundry per hari

b. Lap. Nota Pengambilan, untuk mengetahui siapa saja pelanggan yang mengambil pakaian per hari

c. Lap. Setrika Harian, untuk mengetahui jumlah pakaian yang disetrika karyawan setrika per hari

d. Lap. Pakaian di Rak, untuk mengetahui laporan lokasi penempatan pakaian yang sudah siap diambil pada masing-masing rak

\section{METODE PELAKSANAAN}


Metode pelaksanaan pengabdian berorientasi kepada solusi dari prioritas permasalahan meliputi beberapa tahapan sebagai berikut :

1. Observasi di Usaha Mikro, bertujuan untuk mengetahui lebih jauh mengenai situasi dan kondisi mitra

2. Pengambilan data, misanya: data karyawan, data layanan yang dijual, data nota, data pelanggan, dll bertujuan untuk perancangan database aplikasi yang akan dibuat

3. Desain Aplikasi Manajemen Laundry berbasis Web, bertujuan merancang aplikasi sebelum diimplementasikan, misalnya: desain database, desain jaringan, dan desain interface

4. Implementasi Aplikasi Manajemen Laundry berbasis Web, adalah aktivitas pemrograman untuk mengimplementasikan desain Aplikasi Manajemen Laundry berbasis Web yang telah dibuat pada tahap sebelumnya.

5. Desain Aplikasi Layanan SMS Pelanggan, bertujuan merancang aplikasi Layanan SMS Pelanggan sebelum diimplementasikan, misalnya: desain database, desain jaringan, dan desain interface

6. Implementasi Aplikasi Layanan SMS Pelanggan, adalah aktivitas pemrograman untuk mengimplementasikan desain Aplikasi Layanan SMS Pelanggan yang telah dibuat pada tahap sebelumnya.

7. Pelatihan penggunaan Aplikasi Manajemen Laundry berbasis Web dan Aplikasi Layanan SMS Pelanggan, ditujukan kepada pemilik laundry agar dapat menggunakan aplikasi sesuai yang diharapkan.

\section{HASIL DAN PEMBAHASAN}

Hasil pengabdian kepada masyarakat yang telah dilaksanakan adalah melatih para karyawan dan pemilik dalam penguasaan sebuah sistem manajemen dalam pengolahan data laundry. Sehingga pihak pemilik laundry bisa memantau semua transaksi laundry dan laporan keuangan laundry, untuk karyawan bisa memudahkan dalam proses input transaksi dan pembayaran laundry, sedangkan untuk pelanggan bisa mudah melihat tagihan transaksi dan melihat history transaksi laundry.Adapaun untuk memperlancar kegiatan tersebut, maka diperlukan beberapa komponen yakni perangkat keras dan networking. Perangkat keras yaitu komputer dan modem. Sedangkan networking adalah adanya jaringan internet.Dalam pelaksanaan pengabdian kepada masyrakat dihadiri oleh pengelola dari setiap laundry yakni Bapak Sugiono dan Bapak Khaidir beserta karyawan karyawan. Kegiatan yang dilaksanakan oleh tim pengabdian kepada masyarakat diawali dengan penjelasan tentang program aplikasi yang memudahkan dalam mengelola bisnis laundry yang menunjang pelaksanaan program pengabdian kepada masyarakat. 


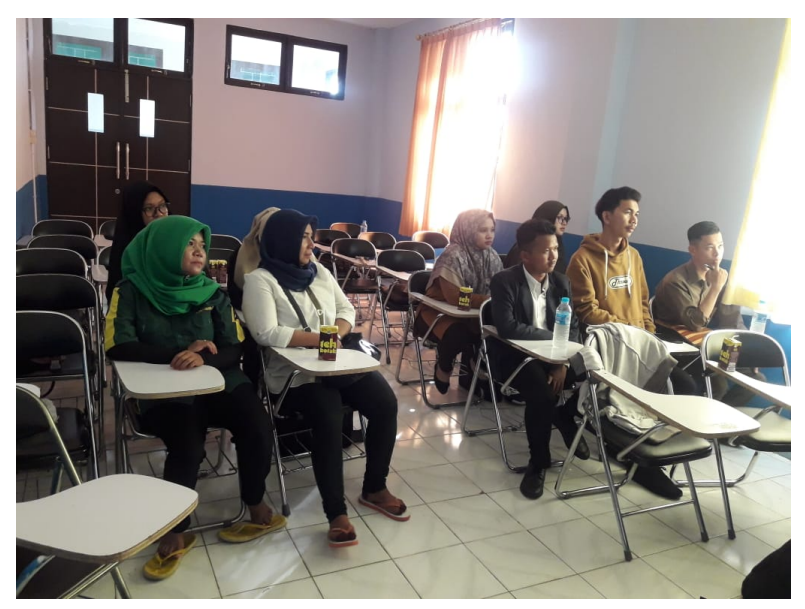

Gambar 1

Pelatihan Penggunaan Aplikasi Manajemen Laundry berbasis Web

Adapun materi penyuluhan yang disajikan adalah "MENINGKATKAN SERVICE QUALITY MANAJAMEN USAHA LAUNDRY DENGAN SISTEM APLIKASI ONLINE".Pada sistem pengolahan data laundry ini menyediakan beberapa fitur diantaranya : login, dasboard, admin, pelanggan, satuan, jenis layanan, transaksi, transaksi operasional, order, laporan, dan pengaturan. Untuk memperlancar pengujian dari aplikasi program, sebelum melakukan pengujian ada beberapa hal yang harus diperhatikan termasuk kelengkapan aplikasi pendukung Adobe Dreamweaver sebagai text editor dan xampp sebagai web servernya Seperti inilah tampilan dashboard admin, disini admin memiliki semua hak akses dari create, delete, select dan update.

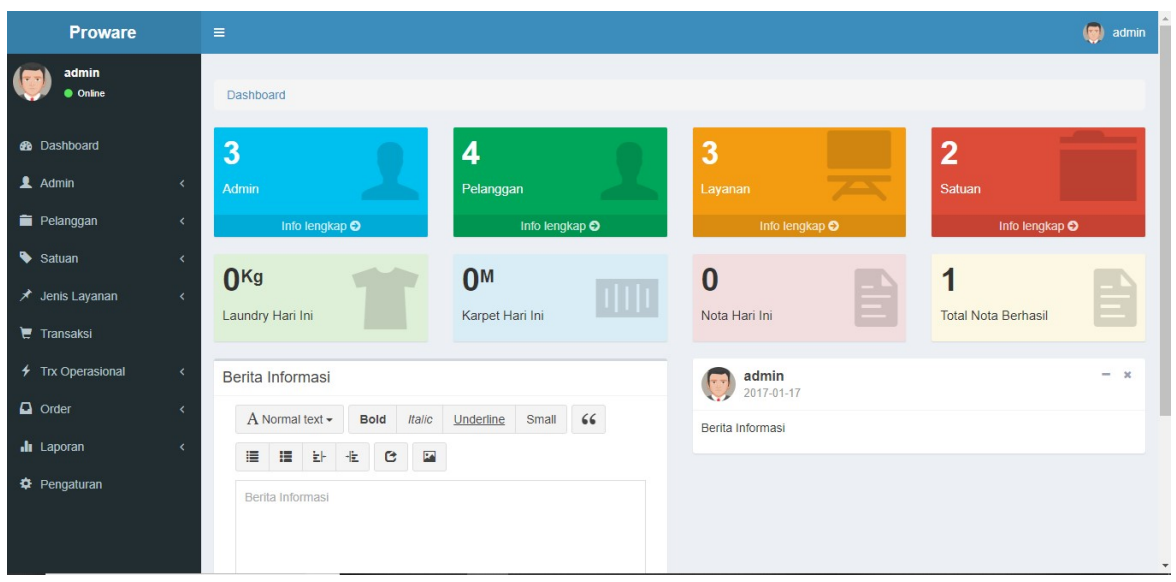

Gambar 2. Tampilan dashboard admin

Kesulitan yang dihadapi dalam pengabdian ini adalah

1. belum terbiasanya para karyawan dalam menggunakan aplikasi laundry, terutama bagi karyawan yang sudah cukup berumur, aplikasi ini dianggap sangat merepotkan 
2. penggunaan aplikasi ini membutuhkan koneksi internet yang stabil serta sistem keamanan yang baik dikarenakan internet adalah jaringan publik yang memungkinkan dimasuki oleh siapapun.

\section{KESIMPULAN}

Penggunaan aplikasi laundry ini terbukti sangat membantu bisnis laundry baik dari segi manajemen keuangan, operasional hingga layanan pelanggan. Namun begitu masyarakat perlu diberikan bekal agar dapat dengan mudah menggunakan aplikasi ini sebagai tools untuk mempermudah pekerjaan mereka

\section{UCAPAN TERIMA KASIH}

1. Bapak Direktur Politeknik Negeri Banjarmasin

2. Bapak Ketua P3M Politeknik Negeri Banjarmasin

3. Bapak Mitra 1 dan Mitra 2

4. Segenap karyawan Mitra 1 dan Mitra 2

\section{DAFTAR PUSTAKA}

Jogiyanto. (2003). Analisis dan Sistem Informasi.Yogyakarta: Andi.

Nasrul. (2016). Analisis Perancangan Sistem Informasi Pemetaan Kompetensi LP3 STT-NF. Journal Teknologi Terpadu, 3-4.

Nasrul. (2016). Analisis Perancangan Sistem Informasi Pemetaan Kompetensi LP3 STT-NF. Jurnal Teknologi Terpadu, 3- 4.

Nugroho, A. (2009). Rekayasa Perangkat Lunak Menggunakan UML dan Java. Yogyakarta:Andi Offset.

Pengertian Yii Framework. (2018, Oktober 5). Retrieved from LPKIA: http://bloglpkia.blogspot.co.id/2013/07/pengertian-yii-framework.html

Santoso, D. (2013). Panduan Pelaksanaan Penelitian dan Pengabdian Kepada Masyarakat diPerguruan Tinggi Edisi IX. In D. Santoso,

Panduan Pelaksanaan Penelitian dan Pengabdian Kepada Masyarakat di Perguruan Tinggi Edisi IX (p. 1). Jakarta: (http://simlitabmas.dikti.go.id).

Solichin, Achmad. 2010. Pemrograman Web dengan PHP dan MySQL. Universitas Budi Luhur, Jakarta. 122 hlm

.Syachbana. (2011). Sistem Informasi Akademik Berbasis Multimedia Pada Lembaga Pendidikan Palembang Technology. Jurnal Teknologi dan Informatika.

Taufiq. (2010, Maret 24). Arsitektur di Rails: ModelView-Controllers. 